\title{
THE STUDY OF KARST DESERTIFICATION MAROS PANGKEP BASED ON LANDSAT 8 OLI IMAGERY
}

\author{
Eko Budiyanto ${ }^{1}$, Nugroho Hari Purnomo ${ }^{1,{ }^{*}}$, Muzayanah ${ }^{1}$, Aida Kurniawati ${ }^{1}$, Ketut Prasetyo ${ }^{1}$, Nastiti Sigra Dewi Maginta ${ }^{2}$ \\ ${ }^{1}$ Jurusan Pendidikan Geografi, Fakultas Ilmu Sosial dan Hukum, Universitas Negeri Surabaya \\ ${ }^{2}$ Sanggar Kegiatan Belajar, Kalilom Lor Surabaya \\ *E-mail: nugrohohari@unesa.ac.id
}

\begin{abstract}
This study aimed to examine the spectral imagery of Landsat 8 OLI that can determine the level of tropical karst desertification Maros Pangkep South Sulawesi. The study method is based on the characteristics of spectral imagery of Landsat 8 OLI. Spectral characteristic analysis was conducted based on derivative index values of Landsat 8 OLI of single-channel spectral values, index spectral values, maximum values, mean, minimal index, and spatial analysis. The results showed that spectral imagery of Landsat 8 OLI can be used as the identifier of the desertification process, that is in band 5 whose maximum value is indicated by the spectral value of vegetation. The karst desertification level in the study area showed that $0.3 \%$ of the regions were strongly desertified or $0,97 \mathrm{~km}^{2}, 4.1 \%$ of medium desertified or $12,03 \mathrm{~km}^{2}, 16.7 \%$ were mildly desertified or $49,17 \mathrm{~km}^{2}$, and $78.9 \%$ were not desertified or $232,57 \mathrm{~km}^{2}$. Observation results for image accuracy shows that strongly desertified areas of land use are mining and cement industries, the medium desertified areas are utilized for marble mining, the mildly desertified areas are utilized for agricultural land, and not desertified areas land are being utilized for tropical rain forest is still dense.
\end{abstract}

Keywords: Karst Desertification; Landsat 8 OLI; Spectral Index.

\section{A. INTRODUCTION}

Karst is a field with hydrological characteristics and landform composed of a combination of soluble rocks and well-developed secondary porosity (Ford, Derek; Williams, 2007). The process is often referred to as the karstification process. Karstification is the working process with an important catalyst of rainwater and carbon dioxide produces a distinctive topographic appearance. The distinctive of karst landform is characterized by the presence of hollow-closed basin with various sizes called Dolin, residual formation or rest of the dissolution process of the hill, and an underground flow system formed by intensive dissolving process.

Karst is highly vulnerable to various natural or human disturbances (Brinkmann \& Garren, 2011; Van Beynen \& Townsend, 2005; Calò \& Parise, 2006; Parise et al., 2008; De Waele, 2009). (Brinkmann \& Garren, 2011)Among other forms of karst degradation, naturally or by human activity is the desertification of rock karst (rocky desertification) (Brinkmann \& Garren, 2011). Desertification of karst rocks is the process of covering the soil surface of karst eroded strongly on the surface or dilution, excessive karst land use 
activity so that the rocks were essentially exposed (Huang, Q; Cai, 2008; Xiong et al., 2009; Yang et al., 2011).

The increasing potential of karst environmental disturbances along with increasing human activity will spur the desertification process. Data of gross regional domestic product of Maros Regency can be used for information on the development activity of the region. The Gross regional domestic product of the Maros regency showed an increase from Rp. 26.54 billion in 2011 to $\mathrm{Rp}$ 46.47 billion in 2015 (Wulandari, 2016). The contribution of economic sectors that have a significant effect on the karst area is the mining and industry sectors. The mining sector in Maros is dominated by open limestone excavation for the cement processing industry. The mining sector increased its contribution from $8.7 \%$ in 2011 to $12.57 \%$ in 2015. At least two large cement factories, Bosowa and Tonasa, as well as the people's mining that utilizes limestone and marble are a threat to karts ecology. Similarly, the manufacturing sector, one of which utilizes mining raw materials, contributed $5.18 \%$ in 2011 to $10.66 \%$ by 2015 (Wulandari, 2016).
Remote sensing data has good potential to study the desertification of karst rock. Remote sensing data enables accurate and intensive monitoring of karst environments. Selection of Landsat 8 OLI imagery because of its ease of result and free, so it can be exploited in the various analysis of spatial earth. This study aimed to examine the spectral imagery of Landsat 8 OLI that can know the desertification level of tropical karst Maros Pangkep South Sulawesi.

\section{B. MATERIALS AND METHODS}

The study conducted in the Karst Maros Pangkep area of South Sulawesi as a research subject, and the object of research was the pixel value of Landsat 8 OLI imagery. The pixel size or spatial resolution of Landsat 8 OLI imagery was $30 \mathrm{~m}$ x $30 \mathrm{~m}$. The main research variables were band 2 to 7 in Landsat 8 OLI imagery, vegetation index based on density, and rock index based on the broad outcrop of rocks.

The classification of karst surface karstification levels using remote sensing data has been carried out by Werz and Hotzl (2007) through orthophoto textural analysis. The part of the orthophoto image which is mostly dark in color with a few patches of 
bright tones is correlated with the karst surface which is mostly covered by soil. On the other hand, parts of the image that are coarsely textured and mostly brightly colored are correlated with well-developed and well-exposed epikarst.

The result of Landsat 8 OLI imagery data was conducted by accessing the NASA portal (HTTP: //landsat.usgs.gov). It was also used GDEM ASTER images $30 \mathrm{~m}$ resolution used as basic data of DEM formation. The other was an earth map of
Indonesia Scale 1: 25.000 as a field guide, as well as contour and land use information sources.

The equipment used included SAGA GIS opensource software used for imagery data processing. In addition, QGIS 2.6.0 opensource software is used for spatial data processing. While the main equipment of the field survey was GPS eTrex Vista HCx.

The research step was begun with imagery processing. Imagery processing shown in Figure 1.

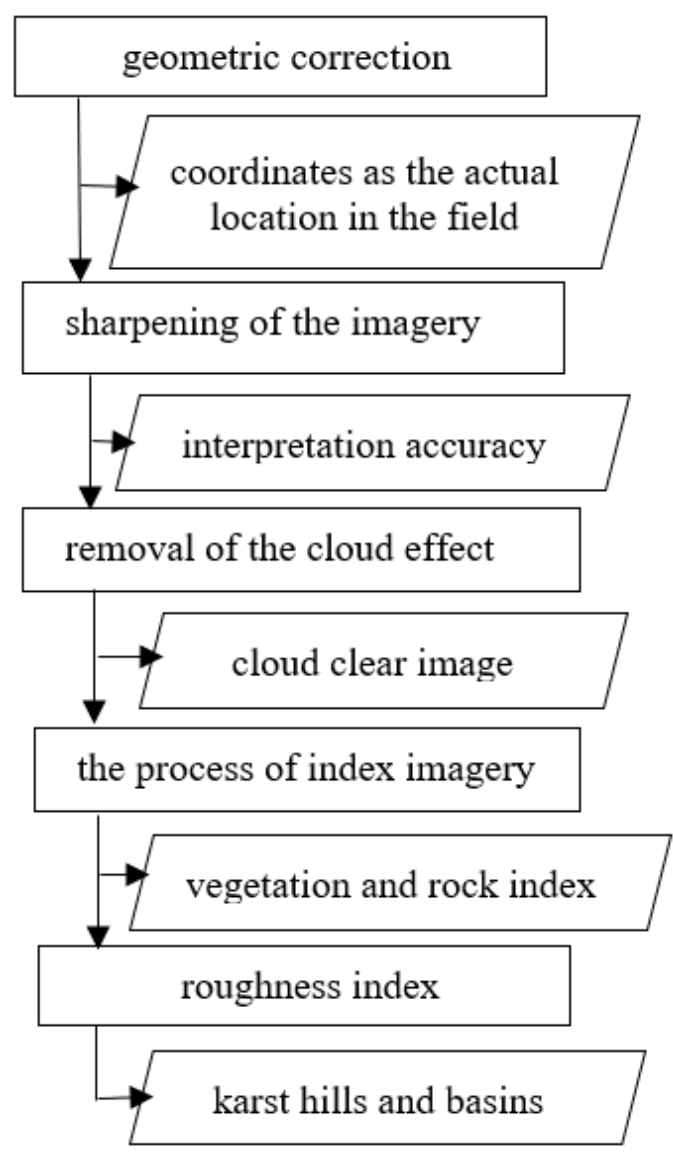

Figure 1. Imagery processing 
The field stage was intended to observe and measure the density of vegetation and rock outcrops. Location of observation and measurement was conducted accidentally. The size of observations in the field was determined at $30 \mathrm{~m} \times 30 \mathrm{~m}$ as much as 30 locations.

Spectral characteristic analysis was performed to obtain spectral data from each sample of observation and measurement area. Spectral characteristics were based on derivative index values of Landsat 8 OLI data of single-channel spectral values, index sample values, maximal values, average, and minimal index values. In addition to this, spatial analysis was also conducted to determine the spread of the index values.

\section{RESULTS AND DISCUSSION}

The study area was limited to areas with karst topography. Karst topography can be identified through spectral analysis of close infrared single spectral imagery. The spectral area visualization of the study is shown in Figure 2.

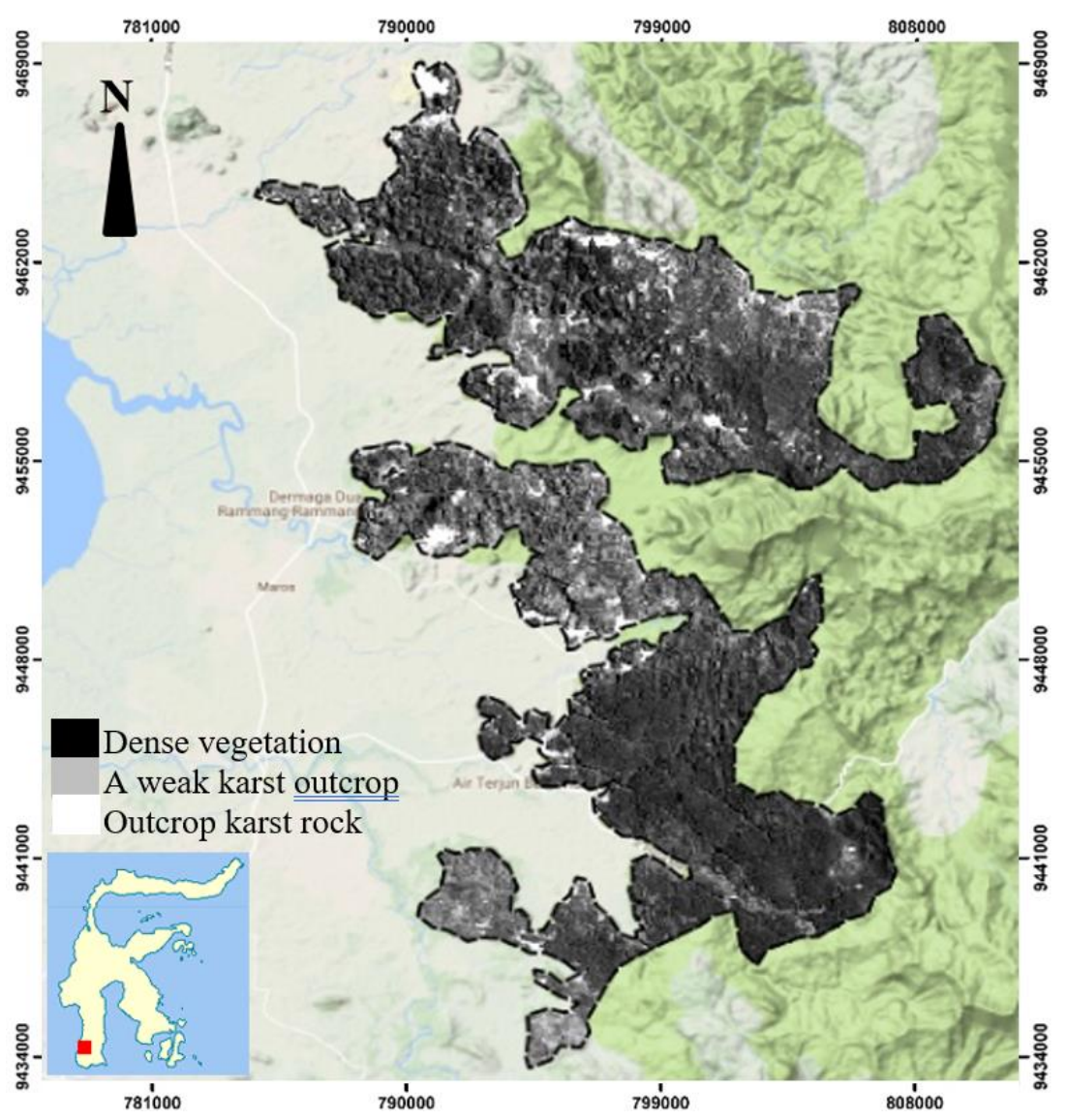

Figure 2. The middle infrared spectral hue of the karst area in a research area (Source: calculation results) 
Based on figure 2, bright hue represents outcrop and karst rock. Areas with very bright hues are shown by strong karst rock outcrops such as in limestone mining areas. The gray hue is shown by a weak karst outcrop with little ground cover on its surface. Small vegetation covers some of the rock's surface. The rough texture is shown by forming large karst hills. The dark hue is shown by a dense vegetation cover. In such areas, the karst surface is covered by vegetation of a dense mixed forest. The karst feature is marked by alignment and crossing straightness.

The straightness pattern is the identifier of karst topography formed by the high difference caused by the fracture of the location. Statistic spatial analysis of visible spectral imagery and infrared shows the distribution of spectral values as presented in Table 1 .

Table 1 shows various spectral ranges of each channel. Variations of the spectral values can be seen clearly in the graph of spectral value distribution as in Figure 3.

Table 1. Spectral distribution of each channel of a research area

\begin{tabular}{ccccccc}
\hline & Band 2 & Band 3 & Band 4 & Band 5 & Band 6 & Band 7 \\
\hline Maxsimum & 19327 & 21912 & 25295 & 30883 & 26562 & 19346 \\
\hline Average & 9794 & 9217 & 8294 & 18406 & 12458 & 8562 \\
\hline Minimum & 9057 & 7759 & 7019 & 8806 & 7331 & 6255 \\
\hline
\end{tabular}

Source : Image processing

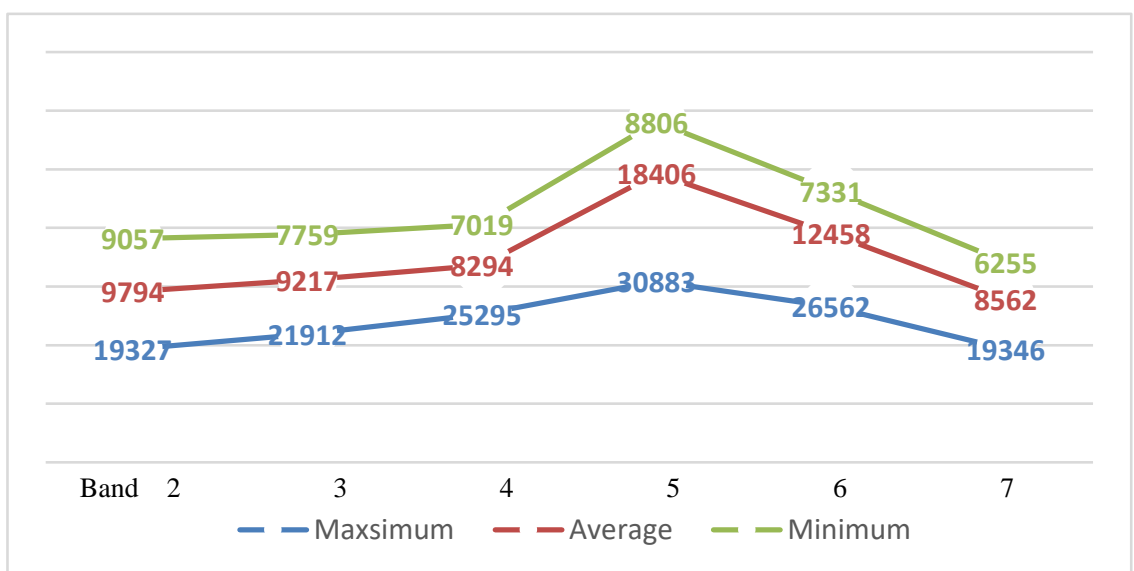

Figure 3. Graph of the spectral distribution of each band in the study area (Source: calculation results)

Based on figure 3 , band 5 is an infrared channel close to the wavelength of $0.85 \mu \mathrm{m}$ to $0.88 \mu \mathrm{m}$. This channel appears to have the largest spectral range compared to the other channel spectral values. The large 
spectral range in this channel shows the variation of karst surface conditions of the study area. The maximum value is indicated by the spectral value of vegetation, while the minimum value is indicated by karst rock outcrops without vegetation cover or soil. A high mean value indicates the number of areas with dense vegetation cover.

Band 5 can be used well for the identification of karst areas in desertified study areas. This is appropriate with Huang, Q; Cai, (2008) establishing the Normalized Difference Rock Index (NDRI) to map the distribution of karst rock outcrops as identifier area that strongly desertified at band 3 and band 5 Landsat TM imagery. In line with this research, the conditions in the Maros Pangkep karst also resulted in an NDRI index that was built based on the spectral characteristics of several land covers. Land cover fractional used as a sample is forest cover titled dense, rare forest, grassland, and karst rock outcrops.

According to Borengasser, M., Hungate, W.S., Watkins, (2008), Landsat imagery band 5 was the peak of close infrared reflection. In areas with relatively close vegetation cover, reflections of these wavelengths become dominant. Band 5 becomes the variable that gives a high value to the pixels that represent the vegetation cover.

Analysis result of spectral imagery value distribution that represents desertification condition in Maros Pangkep karst area. The distribution of karst rock desertification index value in the study area can be seen in Figure 4. Based on the desertification of index imagery is a known distribution of weak, medium, strong desertified, and not desertified areas. The width of each desertified area is presented in Table 2. 


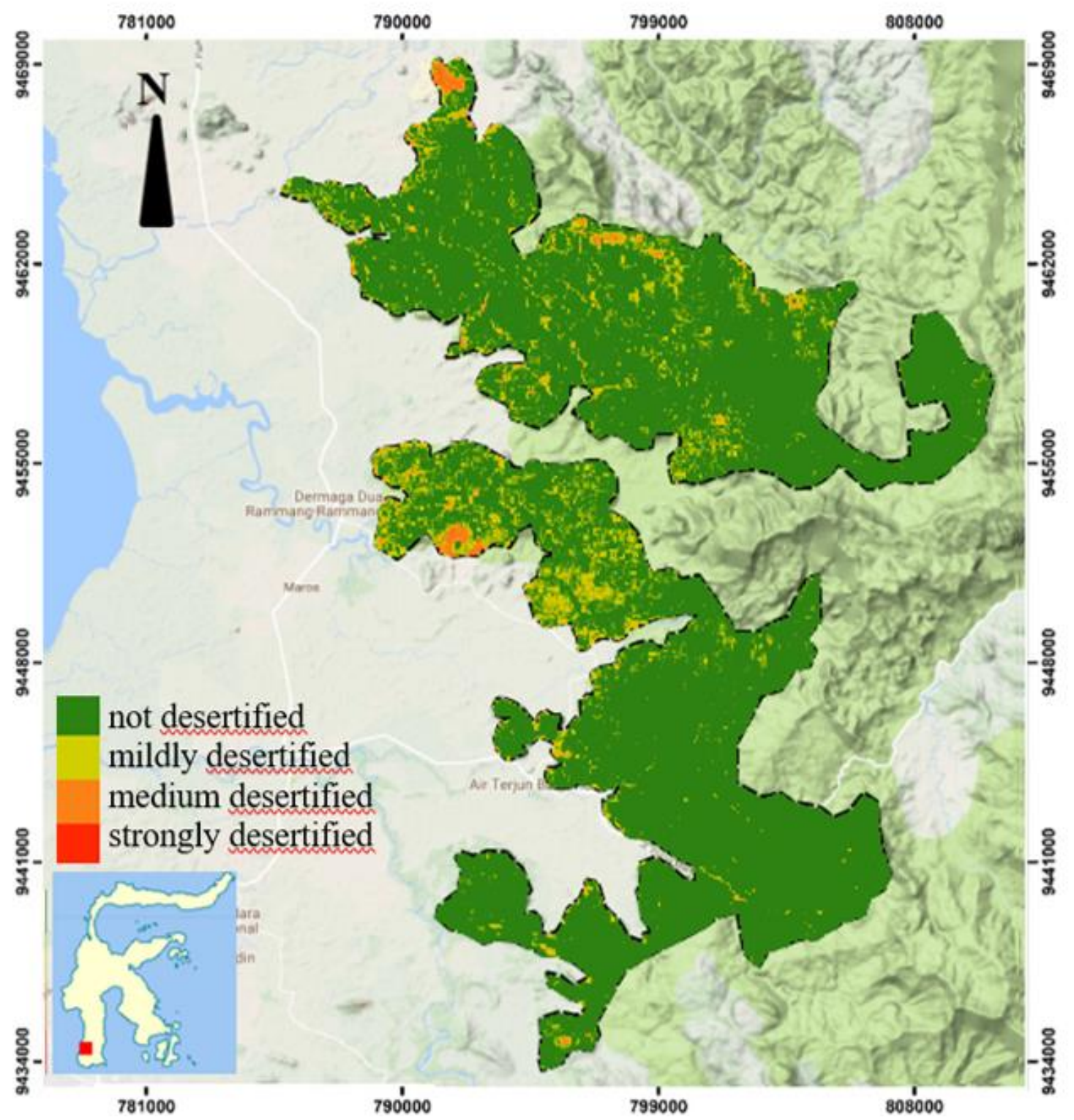

Figure 4. Karst rocks desertification index in the study area

(Source: calculation results)

Table 2. The width of the desertified area in the study area

\begin{tabular}{lccc}
\hline Desertification level & Number of pixels & Luas $\left(\mathrm{km}^{2}\right)$ & $(\%)$ \\
\hline Undesertified & 259440 & 232,57 & 78,9 \\
Weak desertified & 54854 & 49,17 & 16,7 \\
Medium desertified & 13422 & 12,03 & 4,1 \\
Strong desertified & 1085 & 0,97 & 0,3 \\
\hline
\end{tabular}

Source: calculation results and image processing

To prove the accuracy of imagery in band 5, conducted by field observation. Field observations were based on the appearance of imagery that shows the color difference that shows the pixel value as presented in Figure 4. The observations illustrating the land use cover are presented in Figure 5. 
The appearance of not desertified

field conditions is a land-use of tropical rain forests (Figur 4.a). The vegetation of a homogeneous forest with a multilevel canopy is its main character.
This area of observation has not been disturbed by human activities that impact land-use change. Several areas adjacent to Bantimurung National Park are used for forest tourism.
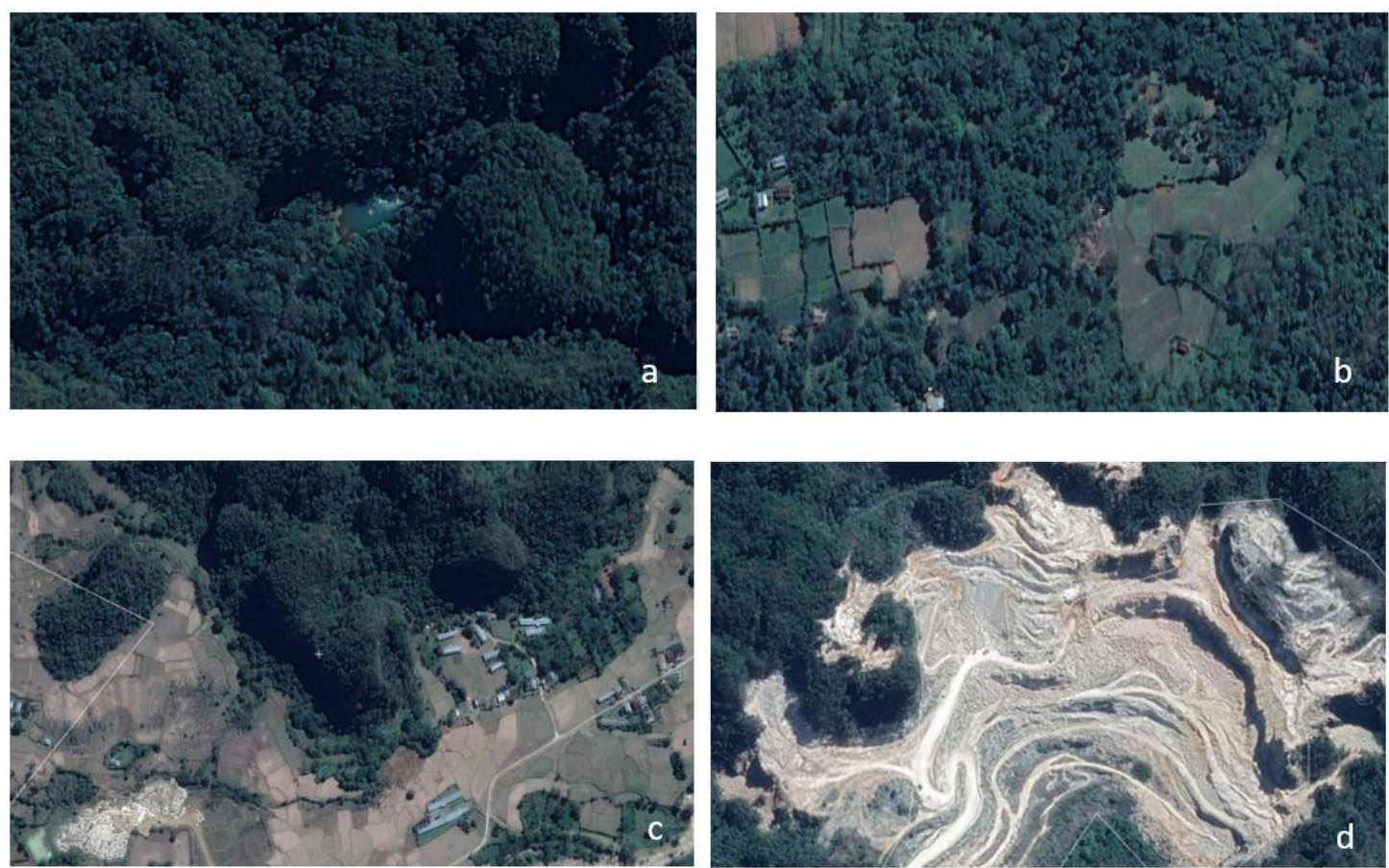

Figure 5. a. Not desertified karst land cover; b. karst land cover of mildly desertified; c. karst land cover of medium desertified; $d$. karst land cover of strong desertified.

(Source: Google map image without processing)

For visibility in the field in mildly desertification conditions, most of it is agricultural land (figur 4.b). Agricultural land develops in shallow valleys around forest vegetation. There is a possibility that this shallow valley is about the former stream. The use of agricultural land still allows the covering of a land surface with plant cultivation vegetation.

Land use as marble mining is the most prominent example in medium desertification conditions (Figur 4.c). Marble mining takes rock material perpendicularly or vertically from a hill wall. The mined hill will show a flat perpendicular wall. Cutting the wall of a hill with heavy equipment affected the retreat of the hill wall resulting in hill width reduction vertically. In general, the vegetation lost from the top of the hill is the hill has been cut. While the hill has not been cut, the natural vegetation is still encountered. 
For strong desertification, land appearance is almost rarely vegetation even no vegetation will be found (Figur 4.d). In general, strongly desertified areas are found in the cement industry. Field observations showed that this area can be divided into three land cover appearances.

The first is the settlement and the cement industry area. In industrial areas found large buildings that are part of the processing system of raw materials into cement. Outside the area, some settlements are limited only by fences and roads. There is very little vegetation in this built area. Some vegetation is only found in the parking area and around the settlement.

The second appearance is the active area of mining of cement raw materials. This area shows the strongest desertification level. The opening of rock layers due to the removal of vegetation and soil is the dominant appearance. While the activity of the miners met was the explosion of rocks, dredging of materials, and transportation of materials. The activity shows the main process of desertification.

The third appearance is ex-mining land is left open. There is no activity in this location, and there is no clear effort or action to cover the land surface in this area.

\section{CONCLUSIONS}

Spectral imagery of Landsat 8 OLI as the identifier of desertification process exists in band 5 whose maximal value is indicated as vegetation spectral value. The results show that there are similarities in band 5 in the desertification process in tropical and non-tropical karsts.

The karst desertification level in the study area showed that $0.3 \%$ of the regions were strongly desertified or $0,97 \mathrm{~km}^{2}, 4.1 \%$ of medium desertified or $12,03 \mathrm{~km}^{2}, 16.7 \%$ were mildly desertified or $49,17 \mathrm{~km}^{2}$, and $78.9 \%$ were not desertified or $232,57 \mathrm{~km}^{2}$. The result of field observation as an effort to prove the accuracy of imagery shows that strongly desertified areas of land use are the mining and cement industries, the medium desertified areas are utilized for marble mining, the mildly desertified areas are utilized for agricultural land, and not desertified areas land are being utilized for tropical rain forest is still dense. Studies need to be continued to determine the rate of desertification. 


\section{E. ACKNOWLEDGMENTS}

Thanks are conveyed to the Institute for Research and Community Service and the Postgraduate Program at the State University of Surabaya for their funding.

\section{F. REFERENCES}

Borengasser, M., Hungate, W.S., Watkins, R. (2008). Hyperspectral remote sensing. Principles and Applications. CRC Press.

Brinkmann, R., \& Garren, S. J. (2011). Karst and Sustainability. In Karst Management (pp. 361-378). Springer Netherlands. https://doi.org/10.1007/978-94007-1207-2_16

Calò, F., \& Parise, M. (2006). Evaluating the Human Disturbance to Karst Environments in Southern Italy. Acta Carsologica, 35(2-3). https://doi.org/10.3986/ac.v35i23.227

De Waele, J. (2009). Evaluating disturbance on mediterranean karst areas: the example of Sardinia (Italy). Environmental Geology, 58(2), 239. https://doi.org/10.1007/s00254008-1600-x

Ford, Derek; Williams, P. (2007). Karst Hydrogeology and Geomorphology. John Wiley \& Sons Ltd,.

Huang, Q; Cai, Y. (2008). Mapping Karst Rock in Southwest China. Mountain Research and Development, 29(1), 14-20. https://doi.org/10.1659/mrd.857

Parise, M., Qiriazi, P., \& Sala, S.
(2008). Evaporite karst of Albania: main features and cases of environmental degradation. Environmental Geology, 53(5), 967-974. https://doi.org/10.1007/s00254007-0722-x

Van Beynen, P., \& Townsend, K. (2005). A Disturbance Index for Karst Environments. Environmental Management, 36(1), 101-116. https://doi.org/10.1007/s00267004-0265-9

Werz, H., Hotzl, H. (2007). Groundwater risk intensity mapping in semi-arid regions using optical remote sensing data as an additional tool. Hydrogeology Journal, 15, 10311049.

https://doi.org/10.1007/s10040007-0202-0

Wulandari. (2016). Maros Dalam Angka. Badan Pusat Statistik.

Xiong, Y. J., Qiu, G. Y., Mo, D. K., Lin, H., Sun, H., Wang, Q. X., Zhao, S. H., \& Yin, J. (2009). Rocky desertification and its causes in karst areas: a case study in Yongshun County, Hunan Province, China. Environmental Geology, 57(7), 1481-1488. https://doi.org/10.1007/s00254008-1425-7

Yang, P., Tang, Y.-Q., Zhou, N.-Q., Wang, J.-X., She, T.-Y., \& Zhang, X.-H. (2011). Characteristics of red clay creep in karst caves and loss leakage of soil in the karst rocky desertification area of Puding County, Guizhou, China. Environmental Earth Sciences, 63(3), 543-549. https://doi.org/10.1007/s12665010-0721-1 